\title{
Staged Embolization with Staged Gamma Knife Radiosurgery to Treat a Large AVM
}

\author{
Adam G. Back, Otto Zeck, Clive Shkedy, Peter M. Shedden
}

Can. J. Neurol. Sci. 2009; 36: 500-503

Treatment of arteriovenous malformations (AVMs) is complicated because of many factors including increasing size, eloquent location, and risk of unacceptable neurological deficits. Each of the treatment modalities, microsurgery, embolization, and stereotactic radiosurgery (SRS), has its pros and cons. Surgery and embolization are limited by location, size, and afferent and efferent vessel anatomy. Stereotactic radiosurgery is limited by size and location, with increasing volume of the AVM resulting in decreasing the therapeutic dose. Many articles address the concern of high dose radiation not being able to be used in SRS over a large volume. ${ }^{1-5}$

Embolization is an endovascular treatment that often precedes surgical excision or stereotactic radiosurgery for the treatment of AVMs. ${ }^{6-8}$ This type of combination is typically utilized for larger AVMs $\left(>3 \mathrm{~cm}^{3}\right)$ in order to reduce the overall size needed to be treated through microsurgical removal or SRS. ${ }^{6,7,9,10}$ Staged gamma knife radiosurgery (GKRS) provides another method of treating larger AVMs and is based on the idea of safe re-treatment; however, unlike re-treatment which occurs approximately three years after the first treatment, staged SRS is multiple treatments over shorter period of time $(\sim 3$ to 8 months). ${ }^{11-14}$

We present a case showing successful obliteration of a large AVM in a 12-year-old male through the use of embolization to initially reduce nidus size followed by staged gamma knife radiosurgery. To the author's knowledge successful obliteration of a large AVM by combining staged embolization with stagedvolume GKRS has not previously been described.

\section{Case Material}

\section{Patient History}

A 12-year-old male presented with complaints of dizziness and severe headaches. The patient did not describe any other complaints. The physical exam and family history were unremarkable. A CT scan was ordered and revealed a large (22.6 cc) and complex left posterior parietal cortical AVM. Further investigations included MRI and conventional 4-vessel angiography.

\section{Treatment Plan}

Microsurgery was deemed inappropriate because of the AVM size. In addition, the volume of the AVM prevented the use of a single gamma knife treatment. A plan was organized that consisted of using staged-embolization to reduce the AVM nidus volume followed by staged-GKRS treatments to complete obliteration. As is important for any staged-GKRS treatment, MRI was used to plan the staged radiosurgical treatments. A flow

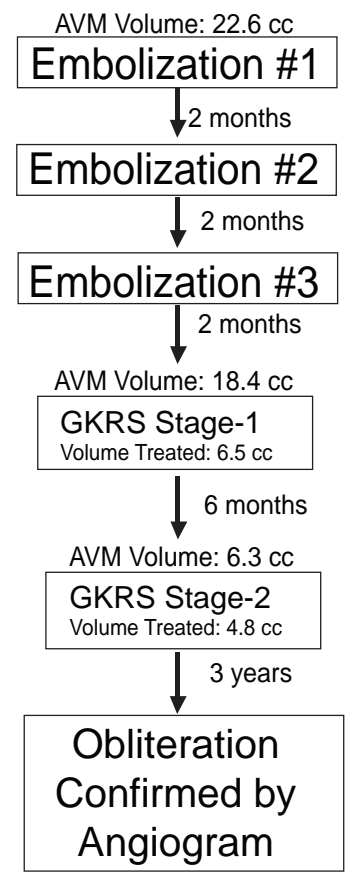

Figure 1: Shows a flow chart of the treatment plan implemented to achieve AVM obliteration. The AVM sizes are shown at three time points: before any treatment $(22.6 c c)$, after all three embolization procedures (18.4cc), and after stage-1 of GKRS (6.3cc). The volumes treated for each stage are also shown. AVM size reduction was greater than volume treated at each stage.

chart of the overall treatment plan is shown in Figure 1.

\section{Embolization}

In order to reduce the volume of the AVM prior to GKRS the patient had three successful embolization procedures using Onyx as the embolization material. Catherization was performed with a transfemoral approach using standard coaxial techniques. The three embolization treatments were performed over a six-month

From the Greater Houston Foundation for Medical Research and Education (AGB, PMS); Memorial Hermann Hospital (OZ, CS), Houston, Texas, USA.

Received SePtember 4, 2008. Final Revisions Submitted March 31, 2009. Correspondence to: Peter M. Shedden, 9200 New Trails, Suite 100, The Woodlands, Texas, 77381, USA. 


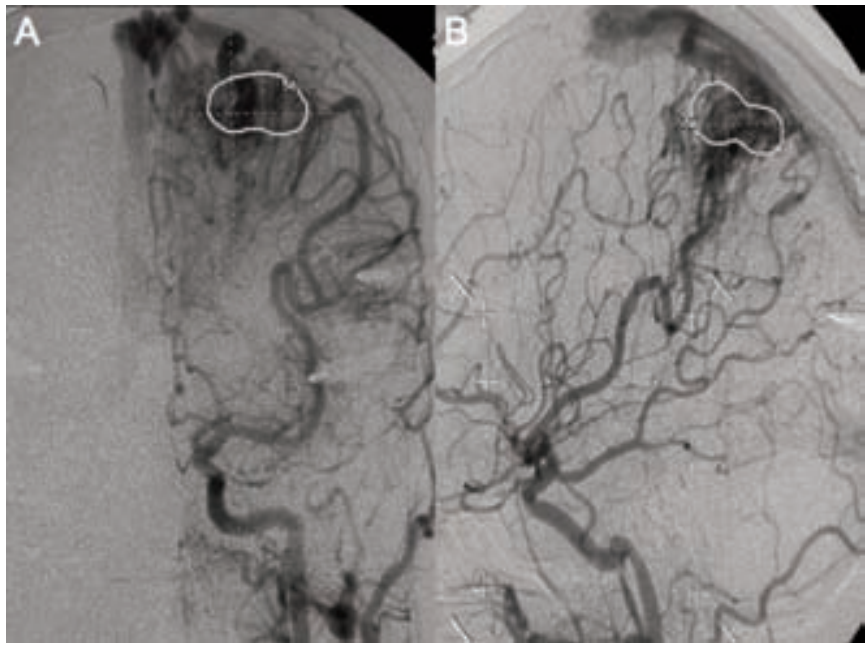

Figure 2: Coronal $(A)$ and sagittal (B) angiographic films post three embolization procedures taken just prior to stage 1 gamma knife treatment. A large AVM is highly evident in this series of angiographic films. The volume treated during stage 1 is shown in the outline.

period with each treatment separated by two-months. Three pedicles were taken in the first embolization procedure while only two were taken in the second and third procedures. Following the third embolization it was felt that the size of the AVM (now 18.4cc) was adequately reduced to allow for 2-staged GKRS treatments to complete the treatment of the AVM.

\section{Staged Gamma Knife Treatment}

Following the last embolization procedure a 2-stage GKRS treatment plan was recommended. Stage-1 of GKRS was performed two-months after the last embolization treatment. Eighteen Gy was delivered to a $6.5 \mathrm{cc}$ region of the total $18.4 \mathrm{cc}$ AVM. Figure 2 shows the angiography that was acquired immediately prior to the stage- 1 procedure.

The second stage of GKRS was performed 6-months after stage-1. The AVM nidus had reduced to $6.3 \mathrm{cc}$ following the first GKRS treatment. The residual AVM was treated with 19 Gy delivered over a $4.8 \mathrm{cc}$ region. Figure 3 shows the angiography that was acquired immediately prior to stage- 2 of GKRS.

\section{Patient Outcome}

Obliteration of the initial 22.6cc AVM was confirmed by angiography three-years after the second stage of the GKRS sequence (shown in Figure 4). The patient suffered no adverse effects from either the radiation treatments or the embolization procedures, and has fully recovered. The patient suffered no complications as of four-years since the last radiosurgical treatment. The combination of embolization and staged GKRS allowed for obliteration to be achieved in this large AVM in a pediatric patient when other methods were deemed high risk.

\section{Discussion}

Several treatment options exist for AVMs including surgical excision, embolization, stereotactic radiosurgery, or a

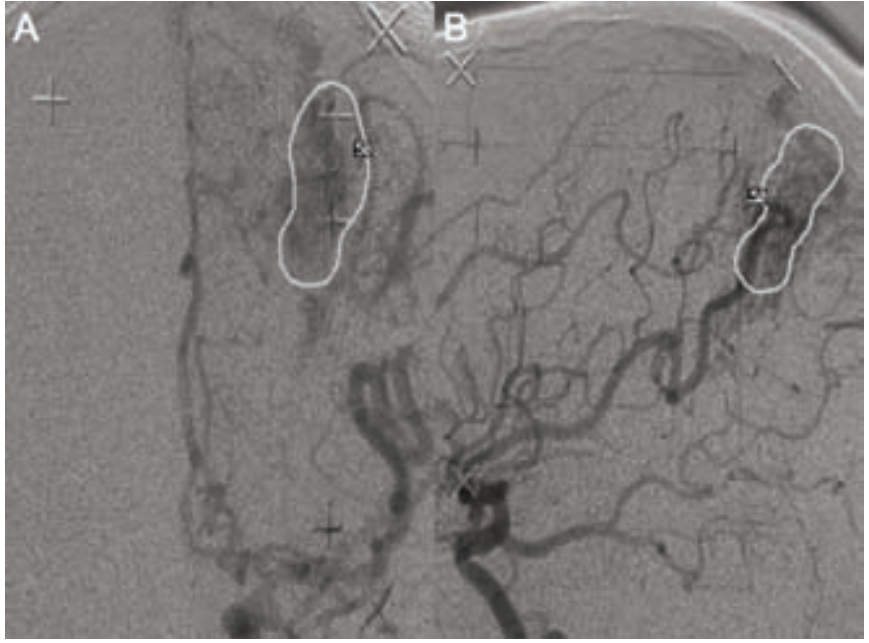

Figure 3: Coronal (A) and sagittal (B) angiographic films 6-months post stage 1 and just prior to stage 2 gamma knife treatment. In this series of angiographic films the AVM appears to be quite reduced in size when compared to the size in the films just prior to stage 2. The volume treated during stage 2 is shown in the outline.

combination of approaches. The ultimate goal of any treatment option is complete obliteration or removal of the AVM eliminating the risk of hemorrhage. The type of treatment modality chosen is primarily based on AVM size and location. None of the treatment options are without risks it is thus necessary to weigh the risk to the patient if the AVM is not treated against the treatment risk. The natural history of AVMs proves useful in helping with this decision.

Several studies have looked at the natural history of AVMs primarily focused on the annual risk of rupture. ${ }^{15-18}$ The majority of AVMs carry a 2-5\% risk of hemorrhage per year with a

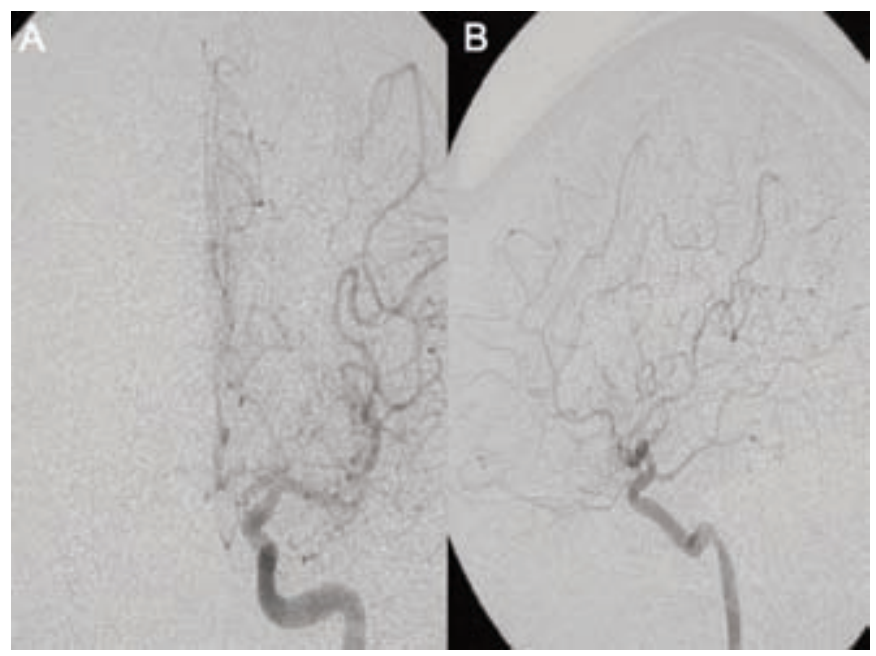

Figure 4: Coronal (A) and sagittal (B) angiographic films approximately three-years post stage-2 of the gamma knife treatment are shown. The large AVM has been completely obliterated and is no longer seen in the angiographic films. 
significant lifetime risk of death if bleeding does occur. ${ }^{15-18}$ The risk of rupture is cumulative with $20-50 \%$ of patients having hemorrhagic events ten years after initial presentation. Risk of hemorrhage is not eliminated until the AVM is completely obliterated. Decisions to treat must be done on the basis of the long-term cumulative rupture risk.

Surgical excision has been shown to be useful in removing AVMs of small volume located in less eloquent areas typically with Spetzler-Martin grades I-III. ${ }^{19}$ If complete excision of the AVM is obtained the risk of hemorrhage to the patient is virtually eliminated post-surgery. The limits of surgical excision occur when the AVM is located in an eloquent location and/or of large volume usually a Spetzler-Martin grade of IV and V. ${ }^{19}$

Radiosurgical treatment of AVMs reduces the AVM volume over a period of several years until obliteration is achieved around three to five years post-radiosurgery. The patient thus remains at risk for bleeding for a period following treatment. Treatment using radiosurgery is based on eliminating the longterm risk of AVM rupture.

Embolization of AVMs eliminates blood flow through the AVM, reducing the nidus volume. Small AVMs have been shown to be successfully treated using embolization alone. Surgical excision of AVMs can be complicated when high vascular flow occurs through the AVM. Spetzler et al reported the use of staged embolization to reduce flow allowing for previously inoperable lesions to be removed through surgical excision. ${ }^{10}$ Larger AVMs theoretically could be reduced in volume through the use of embolization prior to radiosurgery; however, studies have shown a reduction in obliteration rate when embolization precedes unstaged GKRS. 6,7,9,20,21 Although a reduction in obliteration rate is observed for large AVMS (10-20cc) this method may still be useful in treating very large AVMs $(>20 \mathrm{cc})$. The reduction in obliteration rate when embolization precedes unstaged GKRS for large AVMs opened the way for staged GKRS as another method of achieving obliteration in very large AVMs.

The numbers of patients in the few studies on staged stereotactic radiosurgery in the medical literature are limited; however, they are encouraging as an option for patients with AVMs that could not be successfully treated by any other method. ${ }^{18,22,23}$ Staged-volume GKRS allows for smaller portions of the AVM to receive higher doses of radiation over a series of treatments usually separated by six-month intervals as was done in this patient. Higher doses of radiation have been shown to correspond with higher rates of obliteration. The time period between treatments is currently done rather arbitrarily. Studies looking at the interval between treatments would be very valuable although to date it has not been a focus of the literature. This method has been shown to result in good obliteration rates with limited complications. ${ }^{23}$ A concern in treating patients with staged GRKS is that they remain susceptible to hemorrhage through each stage. An additional concern is that after partially treating the AVM the risk of hemorrhage is increased. ${ }^{23}$ Embolization prior to staged-GKRS may provide a method of both reducing AVM volume to be treated as well as reducing the risk of hemorrhage between staged treatments.

The successful use of embolization with a single radiosurgery treatment, although reported at a reduced obliteration rate has previously been described.6,7,9,10,20 The use of staged embolization followed by staged-volume GKRS has not previously been reported in the literature. Using embolization prior to staged GKRS allows for a reduction in nidus volume prior to radiosurgery and may reduce the risk of complications between each stage of radiosurgery. This also allows for higher doses of radiation to be given to the patient, which would increase the patient's chances to achieve AVM obliteration. . $^{1,24-}$ ${ }^{29}$ By combining embolization and staged GKRS it is possible that the patient will need fewer stages of GKRS and have a decreased risk of complications between the treatment stages.

One of the more interesting observations seen in this case is that each stage of the gamma knife treatment reduced the AVM size more than the treated volume. The first stage treated $6.5 \mathrm{cc}$ of the $18.4 \mathrm{cc}$ AVM resulting in a reduction of the AVM volume by $12.1 \mathrm{cc}$. The second stage treated $4.8 \mathrm{cc}$ of the $6.3 \mathrm{cc}$ AVM and was sufficient to achieve complete obliteration of the AVM. Both stages obtained greater AVM volume reduction than the volume treated. This suggests that it may be possible to achieve sufficient reduction in AVM volume by treating a volume that is smaller than the AVM. Focusing on treating the central region of the AVM may allow the periphery of the AVM to be obliterated in conjunction with the central region and allows for higher doses of radiation to be used safely. This treatment possibility would be best tested using a randomized-control trial and should be looked at as a possible way to improve the effectiveness of radiosurgery treatment for AVM's. Focusing on treating the center of the nidus through each stage also has a lower risk of adverse radiation effects compared to fractionation in which different parts of the nidus are treated at each stage. This is likely a result of higher exposure of normal tissue to radiation when fractionation staging is performed.

It is important to treat a patient with an AVM as soon as possible in order to prevent the patient from increased risk of bleeding that occurs with time. This study suggests a potential treatment combination using staged embolization followed by staged GKRS for the successful treatment of large AVMs in patients when other treatment options may not be reasonable. Although embolization prior to staged radiosurgery has been described in the literature, to the author's knowledge combining staged embolization with staged-volume radiosurgery has not previously been described in the literature.

\section{REFERENCES}

1. Friedman WA, Bova FJ, Bollampally S, Bradshaw P. Analysis of factors predictive of success or complications in arteriovenous malformation radiosurgery. Neurosurgery. 2003;52(2):296-307.

2. Izawa M, Hayashi M, Chernov M, Nakaya K, Ochiai T, Murata N, et al. Long-term complications after gamma knife surgery for arteriovenous malformations. J Neurosurg. 2005;102 Suppl: 34-7.

3. Lax I, Karlsson B. Prediction of complications in gamma knife radiosurgery of arteriovenous malformation. Acta Oncol. 1996; 35(1):49-55.

4. Levegrun S, Hof H, Essig M, Schlegel W, Debus J. Radiationinduced changes of brain tissue after radiosurgery in patients with arteriovenous malformations: correlation with dose distribution parameters. Int J Radiat Oncol Biol Phys. 2004;59 (3):796-808 .

5. Miyamoto S, Hashimoto N, Nagata I, Nozaki K, Morimoto M, Taki $\mathrm{W}$, et al. Posttreatment sequelae of palliatively treated cerebral arteriovenous malformations. Neurosurgery. 2000;46(3):589-94.

6. Chang JH, Chang JW, Park YG, Chung SS. Factors related to complete occlusion of arteriovenous malformations after gamma knife radiosurgery. J Neurosurg. 2000;93 Suppl 3:96-101. 
7. Kinouchi H, Mizoi K, Takahashi A, Ezura M, Yoshimoto T. Combined embolization and microsurgery for cerebral arteriovenous malformation. Neurol Med Chir (Tokyo). 2002;42 (9):372-8.

8. Paulsen RD, Steinberg GK, Norbash AM, Marcellus ML, Marks MP. Embolization of basal ganglia and thalamic arteriovenous malformations. Neurosurgery. 1999;44(5):991-6.

9. Dawson RC, Tarr RW, Hecht ST, Jungreis CA, Lunsford LD, Coffey R, et al. Treatment of arteriovenous malformations of the brain with combined embolization and stereotactic radiosurgery: results after 1 and 2 years. Am J Neuroradiol. 1990;11(5): $857-64$.

10. Spetzler RF, Martin NA, Carter LP, Flom RA, Raudzens PA, Wilkinson E. Surgical management of large AVM's by staged embolization and operative excision. J Neurosurg. 1987;67(1): 17-28.

11. Foote KD, Friedman WA, Ellis TL, Bova FJ, Buatti JM, Meeks SL. Salvage retreatment after failure of radiosurgery in patients with arteriovenous malformations. J Neurosurg. 2003;98(2):337-41.

12. Karlsson B, Lindquist C, Steiner L. Effect of Gamma Knife surgery on the risk of rupture prior to AVM obliteration. Minim Invasive Neurosurg. 1996;39(1):21-7.

13. Maesawa S, Flickinger JC, Kondziolka D, Lunsford LD. Repeated radiosurgery for incompletely obliterated arteriovenous malformations. J Neurosurg. 2000;92(6):961-70.

14. Mirza-Aghazadeh J, Andrade-Souza YM, Zadeh G, Scora D, Tsao M, Schwartz M. Radiosurgical retreatment for brain arteriovenous malformation. Can J Neurol Sci. 2006;33(2): 189-94.

15. Brown RD, Wiebers DO, Forbes G, O'Fallon WM, Piepgras DG, Marsh WR, et al. The natural history of unruptured intracranial arteriovenous malformations. J Neurosurg. 2008;68(3):352-7.

16. Hernesniemi JA, Dashti R, Juvela S, Vaart K, Niemela M, Laakso A. Natural history of brain arteriovenous malformations: a longterm follow-up study of risk of hemorrhage in 238 patients. Neurosurgery. 2008;63(5):823-31.

17. Ondra SL, Troupp H, George ED, Shwab K. The natural history of symptomatic arteriovenous malformations of the brain: a 24 year follow-up assessment. J Neurosurg. 1990;73(3):387-91.

18. Sirin S, Kondziolka D, Niranjan A, Flickinger JC, Maitz AH, Lunsford LD. Prospective staged volume radiosurgery for large arteriovenous malformations: indications and outcomes in otherwise untreatable patients. Neurosurgery. 2006;58(1):17-27.
19. Pikus HJ, Beach ML, Harbaugh RE. Microsurgical treatment of arteriovenous malformations: analysis and comparison with stereotactic radiosurgery. J Neurosurg. 1998;88(4):641-6.

20. Andrade-Souza YM, Ramani M, Scora D, Tsao MN, terBrugge K, Schwartz ML. Embolization before radiosurgery reduces the obliteration rate of arteriovenous malformations. Neurosurgery. 2007;60(3):443-51.

21. Mavroidis P, Theodorou K, Lefkopoulos D, Nataf F, Schlienger M, Karlsson B, et al. Prediction of AVM obliteration after stereotactic radiotherapy using radiobiological modelling. Phys Med Biol. 2002;47(14):2471-94.

22. Pendl G, Unger F, Papaefthymiou G, Eustacchio S. Staged radiosurgical treatment for large benign cerebral lesions. J Neurosurg. 2000;93 Suppl:3107-112.

23. Pollock BE, Kline RW, Stafford SL, Foote RL, Schomberg PJ. The rationale and technique of staged-volume arteriovenous malformation radiosurgery. Int J Radiat Oncol Biol Phys. 2000; 48(3):817-24

24. Chang SD, Marcellus ML, Marks MP, Levy RP, Do H, Steinberg GK. Multimodality treatment of giant intracranial arteriovenous malformations. Neurosurgery. 2003;53(1):1-11.

25. Flickinger JC, Kondziolka D, Maitz AH, Lunsford LD. An analysis of the dose-response for arteriovenous malformation radiosurgery and other factors affecting obliteration. Radiother Oncol. 2002;63(3):347-54.

26. Karlsson B, Lax I, Soderman M. Can the probability for obliteration after radiosurgery for arteriovenous malformations be accurately predicted? Int J Radiat Oncol Biol Phys. 1999;43(2):313-19.

27. Karlsson B, Lindquist C, Steiner L. Prediction of obliteration after gamma knife surgery for cerebral arteriovenous malformations. Neurosurgery. 1997;40(3):425-30.

28. Speizler RF, Martin NA. A proposed grading system for arteriovenous malformations. 1986. J Neurosurg. 2008;108(1): 186-93.

29. Yamamoto Y, Coffey RJ, Nichols DA, Shaw EG. Interim report on the radiosurgical treatment of cerebral arteriovenous malformations. The influence of size, dose, time, and technical factors on obliteration rate. J Neurosurg. 1995;83(5):832-7. 